\title{
Alimentos com agrotóxicos ou de base agroecológica: o jogo simbólico de atores sociais
}

\section{Food with pesticides or agroecologically-based food: symbolic game on the field}

\author{
Verônica Oliveira Figueiredo? \\ Maria Claudia Veiga Soares Carvalho \\ Francisco Romão Ferreira ${ }^{3}$ \\ Luciléia Granhen Tavares Colares' \\ Izabela Miranda de Castro ${ }^{4}$ \\ Lucia Maria Jaeger de Carvalho ${ }^{5}$ \\ 1 Universidade Federal do Rio de Janeiro, \\ Instituto de Nutrição Josué de Castro, \\ Departamento de Nutrição e Dietética. Rio de \\ Janeiro-RJ, Brasil. \\ ${ }^{2}$ Universidade Federal do Rio de Janeiro, Instituto \\ de Nutrição Josué de Castro, Departamento de \\ Nutrição Social Aplicada. Rio de Janeiro-RJ, \\ Brasil. \\ ${ }^{3}$ Universidade do Estado do Rio de Janeiro, \\ Instituto de Nutrição. Departamento de Nutrição \\ Social. Rio de Janeiro-RJ, Brasil. \\ ${ }^{4}$ Empresa Brasileira de Pesquisa Agropecuária. \\ Agroindústria de Alimentos-EMBRAPA, \\ Laboratório de Resíduos e Contaminantes. Rio de \\ Janeiro-RJ, Brasil. \\ ${ }^{5}$ Universidade Federal do Rio de Janeiro, \\ Faculdade de Farmácia, Departamento de \\ Produtos Naturais e Alimentos. \\ Correspondência / Correspondence \\ Verônica Oliveira Figueiredo \\ E-mail:veronica@nutricao.ufri.br
}

\section{Resumo}

Destacamos os agrotóxicos como um elemento que pode influenciar no habitus dos sujeitos que participam do contexto da agricultura brasileira assumindo, geralmente, uma posição favorável ou contra o uso desses insumos. Este artigo busca alguns elementos ocultos no universo do alimento com agrotóxicos e, para tanto, apoiamo-nos nas ferramentas metodológicas de Bourdieu, que insurge contra o agir mecânico dos sujeitos e desvela mecanismos de dominação a partir de um jogo de ocultação. Nesse contexto, o produtivismo e a competitividade parecem contribuir para o fortalecimento da crença do desenvolvimento socioeconômico. No campo social, onde há um jogo de disputas em torno do alimento produzido ou não com agrotóxicos, a sustentabilidade surge como um valor capaz de capitalizar os representantes da força hegemônica, que tentam inserir um modo de ressignificar o nome agrotóxicos, dando-lhe uma nova designação, ocultando seu sentido no cotidiano das pessoas. Assim, entendemos que repensar as práticas utilizadas na produção de alimentos pode se constituir uma possibilidade de construir novas formas de transformação social, visando à saúde coletiva.

Palavras-chave: Alimento. Agrotóxicos. Jogo Simbólico. Sustentabilidade.

\section{Abstract}

We emphasize pesticides as a factor that can influence the habits of the subjects that participate in the context of Brazilian agriculture, who usually take a stance for or against the use of 
these inputs. This article aims to analyze some hidden elements in the universe of food with pesticides and, therefore, we rely on the methodology of Bourdieu, making an approach against the mechanical action of subjects; it reveals mechanisms of domination based on a game of concealment. In this context, productivism and competitiveness seem to contribute to strengthening the belief of socioeconomic development. In the field, where there is a set of disputes surrounding the food produced or not with pesticides, sustainability emerges as a value which can capitalize representatives of hegemonic force, trying to insert a way to reframe pesticide names, giving a new designation by hiding their meaning in daily life. Thus, we understand that rethinking the practices used in food production may be a possibility of building new forms of social transformation, aimed at public health.

Key words: Food. Pesticides. Symbolic Power. Sustainable.

\section{Introdução}

No Brasil, o padrão produtivo, fundamentado em um modelo de campo modernizado, vinculado à ideia de progresso, vem tratando a terra como um bem que pode movimentar o mercado, atestado por meio de expressiva participação de produtos agrícolas no Produto Interno Bruto (PIB). ${ }^{1}$ E o agronegócio exerce forte influência nesse cenário. ${ }^{2}$

Esse padrão de produtividade vem sendo estimulado desde a chamada Revolução Verde, iniciada em meados do século XX, que potencializou a estrutura tecnológica nos sistemas produtivos agrícolas, mediante a utilização de insumos químicos (entre eles, os agrotóxicos) e procedimentos biotecnológicos, em detrimento de práticas da agricultura autóctone, ${ }^{3}$ que favorece a diversidade de espécies cultivadas em uma localidade.

A modernização da agricultura, que continuamente vem se especializando, bem como a industrialização dos alimentos, provocou impactos na alimentação, o que nos remete às questões colocadas por Contreras ${ }^{4}$ quanto à insegurança alimentar percebida por uma importante parcela da população.

Para os especialistas, muitas das crises alimentares foram somente "sustos" mais ou menos irrelevantes (casos como: "azeite de bagaço", "vacas loucas", "alimentos transgênicos", "frangos com dioxinas", "hormônios para engorda de gado"...)... Contudo, para a maior parte da população, esses problemas costumam ter outro significado. Evidenciam determinados aspectos "invisíveis" da cadeia alimentar (CONTRERAS, 2011, p. 42). 
Nesse sentido, os agrotóxicos são matérias invisíveis que podem integrar a estrutura química dos alimentos sem, no entanto, ser percebidos pela população, revelando a ideia de que "o consumidor moderno, literalmente, não sabe o que ele come". ${ }^{5}$

O aumento da utilização dos agrotóxicos no Brasil foi mais bem influenciado pela tecnologia implementada nas práticas agrícolas do que pelo aumento da área cultivada. Entre os anos de 2004 e 2008, por exemplo, houve crescimento de 4,6\% da área cultivada, enquanto as quantidades vendidas de agrotóxicos, no mesmo período, atingiram 44,6\%, segundo levantamento do Sindicato Nacional da Indústria de Produtos para Defesa Agrícola (SINDIVEG). ${ }^{6}$ As vendas totais de agrotóxicos, em 2012, revelaram um aumento de 14\% em relação ao ano anterior, em que a movimentação financeira, somente considerando as classes de herbicidas, fungicidas e inseticidas, atingiu um valor em torno de US $\$ 9,1$ bilhões, ${ }^{7}$ comprovando a inserção desses insumos no mercado agrário.

O Programa de Análise de Resíduos de Agrotóxicos em Alimentos (PARA), da Agência Nacional de Vigilância Sanitária, desde 2001, quando foi criado, vem realizando, sistematicamente, avaliação de agrotóxicos em alimentos in natura, que são postos no mercado consumidor. Desse modo, o que tem sido constatado é a ocorrência de uma gama de ingredientes ativos (substância que faz parte da formulação do agrotóxico, com ação sobre os organismos-alvo) em frutas e hortaliças, cultivadas em boa parte dos estados brasileiros. ${ }^{8-11}$

Assim, de acordo com as características dos agrotóxicos e de sua interação com o ambiente, apontadas na definição oficial, ${ }^{12}$ o Estado brasileiro apresenta instrumentos regulatórios para o sistema produtivo agrícola, que se dá por meio de três ministérios, a saber: da Agricultura, da Saúde e do Meio Ambiente. No âmbito de suas respectivas áreas de competência, entre outras ações, cabe a esses ministérios o estabelecimento de diretrizes e exigências, objetivando minimizar os riscos apresentados por agrotóxicos. Essa regulação, na prática, tem se dado em um campo de disputa, onde forças opostas coexistem e podem ser percebidas nos grupos sociais que defendem o uso desses insumos, bem como naqueles que criticam tal uso.

Em uma abordagem crítica, percebemos que nesse contexto político, cada um dos ministérios, como agentes sociais, propõe mudanças de acordo com as regras do próprio jogo simbólico imerso nas disputas políticas.

É preciso lembrar que essas diferentes formas de agir expressam discursos, posições políticas e interesses econômicos legítimos de diversos atores: agricultores, fornecedores de insumos, exportadores, fabricantes de máquinas e equipamentos, agências de financiamento, trabalhadores do campo, empresas alimentícias e diferentes representantes das esferas estatais.

Nesse sentido, o referencial teórico de Bourdieu ${ }^{13-16}$ pode contribuir para iluminar os elementos simbólicos, representados pelas forças de disputa e interesses dos agentes sociais no universo dos agrotóxicos (ou agronegócio), onde valores e práticas culturais influenciam nas estratégias de um complexo jogo simbólico, expressado na concepção "alimentos com agrotóxicos". 
Consumir alimentos saudáveis e livres de agrotóxicos não é uma mera questão de gosto ou estilo pessoal, este consumo gera implicações que extrapolam a comensalidade cotidiana e o jogo de identidades individuais, nacionais ou globais. Diante disso, uma questão se impõe: como ficam as identidades nacionais num mundo governado pelo mercado, pelo fluxo de capital virtual, grandes marcas e empresas transnacionais?

Os vários lados da questão apresentam argumentos positivos, seja o agronegócio ou a agricultura de base agroecológica, as redes de fast-food ou os adeptos da alimentação saudável, as grandes redes de distribuição de alimentos e os pequenos comerciantes, a comida global e a culinária local, enfim, são muitos interesses em jogo, muitas perspectivas antagônicas, e cada um desses atores sociais ressaltando os aspectos positivos e omitindo suas fragilidades. Neste texto, buscaremos compreender a complexidade social contida na concepção "alimentos com agrotóxicos" em uma perspectiva crítica, superando a dicotomia que coloca os atores sociais do lado do bem ou do mal, o que muitas vezes oculta interesses e reduz as possibilidades de pensar o campo da Alimentação e Nutrição.

Desse modo, ao adaptarmos algumas ferramentas conceituais de Bourdieu para o universo do agronegócio, seguimos um método reflexivo de análise de textos publicados na mídia virtual, a fim de observar elementos ocultos no jogo simbólico, disputado nesse universo, de modo a compreender, sob a ótica da socioantropologia, alguns interesses e valores presentes nele.

Diante desse panorama político e social reconhecer um alimento com ou sem agrotóxicos é um condicionante da escolha alimentar, que pode ou não representar exercício de cidadania. Mas como o consumidor leigo, ou seja, o conjunto da sociedade, pode reconhecer o uso dessas "substâncias invisíveis"?

\section{Considerações metodológicas}

Este estudo segue a abordagem sociológica de Bourdieu, na perspectiva de desvelar coisas ocultas, buscando compreender a violência simbólica invisível nas relações sociais. ${ }^{14}$ Na medida em que os elementos simbólicos da relação entre os agentes no campo nem sempre são compreensíveis a um primeiro olhar, Bourdieu faz uma observação sistemática de alguns elementos que estão presentes e ocultos, ao mesmo tempo, no jogo simbólico cotidiano, aplicando suas ferramentas conceituais na análise desses elementos contidos nas relações entre os agentes sociais, a fim de "compreender as estratégias interessadas de manipulação simbólica". ${ }^{15}$

Bourdieu $^{14}$ escolhe o estúdio televisivo e seus bastidores como campo para análise, e nele faz uma abordagem crítica a respeito do modo como um meio de comunicação pode ser utilizado como instrumento de opressão simbólica, considerando que as imagens e discursos veiculados 
pela televisão, mais especificamente, pelo jornalismo, são carregados de ideologias e podem influenciar na construção social de uma realidade que tem poder para produzir um efeito social. Ele insurge contrário ao agir mecânico do sujeito sem que haja espaço para o pensamento crítico. O jornalismo não sendo "muito propício à expressão do pensamento, estabelece um elo negativo entre a urgência e o pensamento", ${ }^{14}$ no entanto, "o pensamento [filosófico] é uma forma capaz de nos iluminar interiormente e de iluminar o caminho diante de nós, permitindo apreender o fundamento onde encontremos significado e orientação". ${ }^{17}$ De acordo com Bourdieu, ${ }^{14}$ o pensamento, em velocidade acelerada, expressa um jogo através de ideias feitas, as quais seriam admitidas por muitos, consideradas convencionais e comuns.

Para nos aproximarmos das ideias e convenções acerca dos alimentos com agrotóxicos, exploramos em detalhes os textos informativos veiculados no sítio eletrônico da Associação Brasileira de Produtores de Soja (Aprosoja Brasil), ${ }^{18}$ no período de outubro de 2012 a novembro de 2013, utilizando a palavra-chave "agrotóxico". Consideramos que esses discursos expressam interesses dos agentes presentes nesse contexto social, que estão articulados com a trajetória histórica de construção desse espaço e, ao mesmo tempo, impregnados com elementos da cultura. Assim, interpretamos o discurso em torno dos agrotóxicos, à luz de alguns conceitos de Bourdieu, a fim de captar o sentido oculto deste discurso.

A escolha desse meio de informação baseou-se em sua abrangência, uma vez que os textos ali publicados são de livre acesso e também por representar produtores de soja, que têm como prática agrícola o uso de agrotóxicos, sendo estes insumos os elementos centrais do discurso desses atores.

Tratada principalmente como commodities no contexto da agricultura global, a soja é um produto que apresenta ampla inserção no mercado nacional ou internacional e, de acordo com o Sindicato Nacional da Indústria de Produtos para Defesa Vegetal (SINDIVEGa), ${ }^{7}$ este cultivo é responsável por absorver o maior volume de comercialização de agrotóxicos, com $47 \%$ do total utilizado em 2012.

\section{Os agentes sociais do jogo simbólico}

Diferentes capitais simbólicos estão colocados à mesa na discussão acerca dos agrotóxicos ou do consumo de alimentos de base agroecológica, vários atores sociais estão no jogo e cada um deles utiliza os sentidos atribuídos ao alimento a seu favor. O consumo representa também uma questão política, a do controle da redistribuição das riquezas de um país entre os grupos sociais e entre as nações ricas e pobres, e é nesse quadro que se situa a emergência de um novo consumo

a Sindicato Nacional da Indústria de Produtos para Defesa Agrícola (SINDAG), fundado em 1941. A razão social foi alterada para Sindicato Nacional da Indústria de Produtos para Defesa Vegetal (SINDIVEG). 
político. Um discurso que afirma ser possível tornar a sociedade mais justa levando em conta o próprio mercado como regulador das demandas sociais.

Consideramos que a livre publicação de textos na mídia eletrônica permitiu aos agentes, representantes do agronegócio, uma liberdade de expressão e manifestação de argumentos de convencimento para a comercialização de alimentos com o uso de agrotóxicos, podendo ocultar ou não seus interesses, intenções e preferências relacionados à produção e comercialização da soja.

Desse modo, o que é possível construir em termos de capital e prestígio em função da posição que os representantes do agronegócio assumem? E qual seu poder de definição de regras na disputa existente nesse jogo simbólico em torno do uso dos agrotóxicos?

No campo da Alimentação e Nutrição, os agentes sociais representam forças conflituosas que disputam e assumem posições de embate de acordo com seus argumentos, interesses e pressupostos nem sempre explícitos quanto ao uso dos agrotóxicos. O cidadão comum, leigo nessas questões, representa a grande parcela da sociedade que consome os produtos e desconhece as questões científicas, os riscos sanitários, os interesses envolvidos e as disputas desse campo. O consumidor busca uma alimentação saudável, no entanto, não faz ideia dos discursos, práticas, saberes e interesses que estão em jogo. Mas embora desconheça a forma como o jogo acontece, é em nome dele que os atores, agentes e instituições falam, todos buscam "o bem comum”, cada um com suas armas.

Nesse jogo simbólico, os produtores de soja se posicionam a favor do alimento com agrotóxicos, cuja produção envolve a monocultura desenvolvida na conjuntura do agronegócio brasileiro. As instituições governamentais, na figura dos diferentes ministérios, participam desse jogo de forças com diferentes propósitos, em diferentes momentos políticos, históricos e sociais. A concepção “alimentos com agrotóxicos", no contexto político, está imersa nesse jogo simbólico em que os agentes governamentais podem ou não assumir lados opostos, modificando seus posicionamentos na prática do jogo. Esses agentes são detentores de poder para promover adaptações emergenciais no sistema legislativo que orienta a agricultura brasileira, assim como para legitimar e atribuir "novos poderes" a um ministério ou outro para a tomada de decisões quanto ao uso ou desuso de um princípio ativo de agrotóxico sobre determinado cultivo.

No entanto, os agentes governamentais se misturam com os representantes do agronegócio e tornam a visibilidade dos interesses do jogo obscura, obtendo força por esse artifício. Essa dissimulação é estratégica para capitalizar os agentes, e também para protegê-los de seus envolvimentos ilícitos que legitimam o conflito de interesses daqueles sujeitos que operam como representantes do poder estatal na posição de coempresários da agricultura ao mesmo tempo. Situação em que esses agentes, entre outras formas de identificação e atuação na política brasileira, podem ser reconhecidos na bancada ruralista, ${ }^{2}$ onde os sujeitos ocupam uma posição aparentemente neutra, porém vinculada diretamente às atividades agrícolas, ou são favorecidos por grupos ligados a elas. Sabemos que a luta muitas vezes é desigual, os verdadeiros interesses 
nem sempre são (ou podem ser) revelados, existe uma assimetria de discursos e estratégias. Os representantes dos atores sociais com maior peso político e econômico atuam abertamente no Legislativo, no entanto, os interesses do trabalhador do campo, do cidadão que consome os produtos agrícolas na cidade e o conjunto da sociedade nem sempre estão presentes nos fóruns de debates em condições de igualdade.

Bourdieu ${ }^{14}$ discute essa estratégia de ocultamento na perspectiva da mídia jornalística, que revela o que é 'necessário', de tal maneira que nos instiga a buscar significados ocultos nas entrelinhas, ou mesmo nas informações que não foram explicitadas. Nos textos pesquisados foi possível identificar 'as ideologias' como um termo recorrente no discurso do agronegócio, mas que pode ocultar um significado de depreciação de outra forma de produção, como as que não utilizam agrotóxico.

Observamos um sentido depreciativo que encobre o interesse de desvalorizar o capital simbólico do alimento de base agroecológica: por um lado, os agentes representantes do agronegócio se autodenominam 'os produtores de alimentos', ocultando o nome agrotóxico, como será discutido à frente, e buscam valor em seu produtivismo em larga escala; por outro, atribuem às 'ideologias' a produção de ideias em detrimento à de alimentos. Os produtores e consumidores da agroecologia, bem como o Governo, na figura, principalmente, do Ministério Público (MP), são denominados ‘ideologias' quando seguem regras desfavoráveis à produção em larga escala de soja, como colocado em um trecho publicado no sítio eletrônico consultado: “(...) Infelizmente, muitos representantes do MP têm apenas discurso e ideologia e isto é ruim ao Brasil e precisa ser enfrentado...”.

As ações conduzidas pelo MP, na maioria das vezes, apresentam-se no discurso como insignificantes ou irrelevantes, desvalorizando o papel desse órgão e, consequentemente, o de qualquer grupo social que se alinhe às práticas agroecológicas. Isso pode ser visto quando no discurso é apontada a ineficiência da burocracia brasileira em virtude dos 'longos' prazos necessários para o processo de liberação de um novo princípio ativo ou, ainda, quando um ministério, por possuir tal competência, julgue necessária a rediscussão do uso de determinado agrotóxico, buscando a avaliação (ou reavaliação) toxicológica do mesmo, que pode ser conduzida pela Agência Nacional de Vigilância Sanitária ou pelo Instituto Brasileiro do Meio Ambiente e dos Recursos Naturais Renováveis. No entanto, em alguns casos, ainda que o MP peça a suspensão de princípios ativos presentes nos agrotóxicos, a justiça pode julgar em favor do uso desses insumos, conforme notícia divulgada no jornal eletrônico Agrodebate, ${ }^{19} \mathrm{em}$ que o pedido de suspensão para agrotóxicos com princípio ativo 2,4-D (2,4-diclorofenoxiacético) foi negado.

No contexto acima, 'a ideologia' do MP é banalizada, apresentando um sentido negativo do ser ecológico, transformando este valor em algo comum, sem importância, tentando fazer com que os agentes sociais que se harmonizam com o ser ecológico ocupem uma posição desgastada e descapitalizada no jogo simbólico. Alguns representantes dos sistemas de produção de alimentos 
orgânicos podem se harmonizar com o ser ecológico, e também com o agronegócio, desde que estejam afinados a uma agricultura produtivista, seguindo as regras que privilegiam este modo de produção. Um alimento orgânico e seus produtores são valorizados pelo agronegócio quando aceitam e perpetuam as suas regras no contexto da agricultura brasileira, na lógica do produtivismo e da competitividade, distanciando-se dos preceitos da produção de alimentos de base agroecológica. Nesse sentido, a agricultura orgânica se apresenta como uma possibilidade de manobras simbólicas no jogo: por um lado, pode se articular com o produtivismo do agronegócio, e por outro, pode se aliar 'às ideologias', no que diz respeito ao meio ambiente com alimento sem agrotóxicos e com a promoção de ações sustentáveis que protejam o solo do desgaste.

Nos textos analisados, o discurso midiático acerca do uso de agrotóxicos apresentou, ao mesmo tempo, um modo de compreensão da realidade, um instrumento de conhecimento e um modo de reprodução da ordem social. Os discursos publicitários cumprem assim uma função política de instrumento de legitimação da dominação. Assegura a manutenção da ordem dominante, os interesses das empresas e a integração fictícia da sociedade, assegurando seus lugares e distinguindo-os. Contribui, portanto, para a desmobilização da sociedade, para a legitimação das hierarquias e para reforçar as distinções dissimuladas. As ideologias do agronegócio servem a interesses particulares que se apresentam como universais, portanto, os agrotóxicos são identificados como um avanço tecnológico, um benefício social e um direito do cidadão, à medida que torna visível e fundamental o uso de agrotóxicos para a produção de alimentos em larga escala.

\section{A sustentabilidade como capital simbólico}

A partir da ECO 92, ${ }^{20}$ a sustentabilidade assume um significado de um viver em sociedade, com os seus negócios, economia e tecnologias de modo a não interferir na capacidade de a natureza sustentar a vida para outras gerações. O ser sustentável denota uma integração de três dimensões: a social, a econômica e a ambiental.

A sustentabilidade nos textos analisados se apresenta como um valor capaz de capitalizar o sujeito do agronegócio, contribuindo com a manutenção de uma posição privilegiada e, concomitantemente, servindo de argumento no texto para defender seu interesse mercadológico: “(...) Hoje no campo se busca ganhos de produtividade e redução de custo. Trata-se da sustentabilidade da atividade, produzir mais na mesma área a custos menores...".

A preocupação dos produtores para diminuir o custo da produção de soja envolve o elevado preço dos agrotóxicos e se expressa como uma barreira a uma prática sustentável em falas com um tom de reivindicação e injustiça, como:

O que vai mais impactar a produção de soja é o custo dos defensivos que tem subido muito...;

(...) estamos vendo muito abuso de preços de inseticidas no campo... 
Nesse sentido, o preço alto dos defensivos agrícolas assume o papel de não sustentável. Ao avaliarmos a elevação dos preços desses insumos através dos dados do SINDIVEG, constatamos que a comercialização dos agrotóxicos permitiu um faturamento no setor de defensivos agrícolas, em 2013, de cerca de US\$ 10.500 bilhões, $8 \%$ superior a 2012, b e este aumento foi determinado principalmente por culturas como a soja, em função do caso da lagarta Helicoverpaarmigera, estabelecendo-se, assim, um ciclo entre a ocorrência de uma praga e o faturamento financeiro de empresas que vendem tais insumos. Portanto, ainda que essas empresas componham a estrutura do agronegócio, os agricultores de uma monocultura, em um panorama onde o custo da produção é elevado, reivindicam a revisão dos preços abusivos dos agrotóxicos praticados no contexto da agricultura brasileira, o que traria uma redução dos custos da produção, viabilizando, na visão desses agricultores, uma prática sustentável na produção de alimentos.

A rotação técnica de variar o tipo de agrotóxico no cultivo é utilizada tanto para diminuir o custo de produção, o que gera competitividade entre as empresas que fabricam e comercializam estes insumos, quanto para diminuir os danos ambientais, entendendo que o uso continuado do mesmo princípio ativo não é considerado um manejo de cuidado ambiental. Nesse contexto, interessa-nos refletir: o menor custo de produção, decorrente do barateamento dos agrotóxicos, contempla uma dimensão econômica da sustentabilidade? Fica claro que uma diminuição de custos no preço final do produto interessa a todos, mas levando-se em conta as questões de Gadotti, ${ }^{21}$ seria esse uso o melhor possível para todos em termos de sustentabilidade? A dimensão ambiental seria contemplada com uso continuado ou com a rotação do ingrediente ativo no cultivo? E quanto à dimensão social, como fica a saúde dos trabalhadores rurais e dos consumidores finais dos alimentos comercializados com agrotóxicos?

Os sujeitos comprometidos com um modo de produção baseada na tecnologização agrícola desenvolvem uma sustentabilidade débil, segundo Atkinson, ${ }^{22}$ representando certa facilidade em substituir o capital natural por capital humano ou manufaturado, justificado pelo ganho de capital econômico. Aqueles que se sustentam em uma produção de base agroecológica são tratados por este mesmo autor como praticantes de uma sustentabilidade forte, onde o capital natural, o humano e o manufaturado se complementam e são insubstituíveis entre si. As experiências acumuladas no contexto da produção agroecológica, ao considerarmos a dimensão ambiental, demonstram práticas de recuperação de solos já explorados, tornando possível a execução das atividades agrícolas sem a intervenção de agrotóxicos. Aliado a este modo de manejo da terra, os atores representantes da ecologização da agricultura ${ }^{3}$ valorizam as ações de promoção de saúde do sujeito participante desse espaço, além do cuidado com o ambiente, retratado pela recuperação ou preservação da flora, fauna e nascentes de água.

b Os dados estatísticos do SINDIVEG foram adquiridos por e-mail e encontram-se arquivados. 
A aproximação da dimensão social da sustentabilidade nos textos analisados se relaciona às práticas de cultivo que utilizam agrotóxicos, por serem colocadas como solução para suprir uma necessidade vital da humanidade - a fome -, apresentando-se como um construto desse espaço, evidenciada nesta afirmação:

(...) Nas campanhas contra o uso desses insumos - necessários e sem os quais a humanidade seria condenada a passar fome -é importante que se diga: os orgânicos não são capazes de alimentar a todos...

Analisando numa perspectiva produtivista, a solução para a questão da fome está associada à produção em larga escala, e o uso de agrotóxicos se torna imprescindível, no entanto, analisando alguns fatores sociais, políticos e históricos, podemos pensar se na Revolução Verde, ou em outros momentos, em que o lucro foi o principal regulador da produção de alimentos, se a solução para a sustentabilidade é esse tipo de produção em larga escala? Compreendemos que numa economia sustentável a questão da fome não pode ser analisada fora do contexto sociocultural e político de nossa história de geração de desigualdade social, pois historicamente é possível compreender que "[...] as propriedades simbólicas, mesmo as mais negativas, podem ser utilizadas estrategicamente em função dos interesses materiais e também simbólicos do seu portador". ${ }^{15}$

Em uma sociedade capitalista e produtivista, as disputas aparecem de forma dissimulada e nem sempre explícita, com argumentos bem construídos que operam como princípios de seleção ou exclusão do uso de agrotóxicos sem serem formalmente enunciadas. Nesse sentido, os agentes sociais do agronegócio revelam uma capitalização que não é somente econômica, mas de prestígio e poder, quando, no jogo de disputas, enfatizam a incapacidade de outros grupos manterem alta a produção de alimentos sem agrotóxicos. Esta é uma situação que parece ser uma estratégia de manutenção de uma posição privilegiada do agronegócio nas disputas do jogo simbólico. Por outro lado, a rejeição de alimentos com agrotóxicos pelos produtores agroecológicos e consumidores expressa a dimensão social da sustentabilidade que contra-argumentam que essa comida com agrotóxicos representa um risco à saúde do trabalhador rural e consumidor. Segundo Carvalho e Luz, ${ }^{23}$ a sustentabilidade do planeta motiva a construção de uma comida natural, uma produção não poluidora da natureza e tão pouco depredadora do solo e do ecossistema que se constrói nos grandes centros urbanos como o Rio de Janeiro.

Considerando que a sustentabilidade é um tema de relevante visibilidade no atual contexto social, estrategicamente, esses agentes o inserem em seus textos no sítio, ainda que, talvez, sua abordagem esteja na condição apresentada por Bourdieu, ${ }^{15}$ como algo "construído de tal maneira que adquire um sentido que não corresponde absolutamente à realidade”, pois mostra o sustentável sob a perspectiva de seus próprios interesses lucrativos. Há uma canalização deste conceito para 
legitimar o uso de agrotóxicos, em que o agronegócio, enquanto "sistema simbólico, cumpre a sua função política como instrumento de imposição ou de legitimação da dominação [...]". ${ }^{15}$

No estudo de Furtado, ${ }^{24}$ vemos que a lógica de um regime capitalista é continuar gerando lucros através da intensificação da exploração da natureza e dos povos, em um movimento em que há extinção de culturas, territórios e legados patrimoniais históricos. Pequenos agricultores e pescadores questionados a respeito das responsabilidades e impactos desiguais gerados pelas mudanças climáticas demonstram que as camadas mais desfavorecidas da população são as que suportam uma parcela desproporcional da destruição ambiental. Percebemos que, ainda que esse contexto político-econômico seja marcado pelo consumismo, individualismo e, não raramente,pela injustiça social, o desenvolvimentismo se destaca como uma crença e a produtividade se torna um meio possível de se chegar ao 'desenvolvimento socioeconômico'.

Nesse sentido, o agrotóxico é um valor positivo que capitaliza o sujeito no contexto do agronegócio, pois possibilita ganhos de produtividade para o agricultor, além de proporcionar o desenvolvimento social do país. Esta é uma ideia recorrente no discurso deste, que destaca a importância da quantidade do alimento produzido, em uma lógica do quanto mais, melhor, ilustrada nas seguintes falas:

(...) afinal se espera colher alguns milhões de toneladas a mais...;

Precisamos encarar a realidade, os defensivos são necessários, pois sem eles o país nunca alcançaria recordes de produção.

Os participantes do espaço social onde se destaca o modelo de cultivo produtivista valorizam as transações mercadológicas, atribuindo ao sistema agropecuário produtivista capacidade de promover o desenvolvimento econômico e social do país. Portanto, a produtividade, aliada à sustentabilidade, são veículos - assuntos-ônibus -, como dito por Bourdieu, ${ }^{14}$ posto que o sentido que estes conceitos assumem no discurso é de "lugar-comum", em razão da percepção favorável que apresentam na conversação cotidiana, desempenhando um papel de fácil assimilação pelo sujeito. Assim, são utilizados como estratégias para uma "comunicação instantânea", incitando um valor positivo para os alimentos com agrotóxicos.

Distantes da intenção de dicotomizar a qualidade do alimento como 'bom ou ruim' produzido nos espaços sociais abordados até aqui, buscamos compreender algumas características desses lugares no intuito de estimular a reflexão crítica do que está posto para o nosso consumo. Entendemos que a cadeia alimentar é complexa, por isso, exige a construção de um pensamento capaz de integrar muitos elementos simbólicos presentes em qualquer que seja o sistema de produção e comercialização dos alimentos. Em sua teoria, Bourdieu ${ }^{14}$ aponta para as fatias de mercado do mundo jornalístico 
"como indicadores das relações de força existentes entre emissoras que concorrem entre si de maneira invisível”. Isso nos parece ser também uma realidade nas relações existentes nos espaços sociais que fomentam alimentos com agrotóxicos, bem como nos que produzem alimentos de base agroecológica, se pensarmos que os detentores de um sólido capital (econômico/simbólico) tem condição de determinar a escala de valores mais favorável a seus produtos.

\section{Agrotóxico: uma palavra quase oculta}

Bourdieu ${ }^{13}$ concede às palavras importante papel de dominação no mundo televisivo, atribuindolhes profunda responsabilidade sobre o que, de fato, se quer revelar.

Se considerarmos que todo espaço social é caracterizado, entre outros elementos, por palavras e termos que propagam, no presente estudo percebemos a variação do sentido que o nome agrotóxico assume nos diferentes contextos sociais. As várias terminologias revelam a multiplicidade de visões que cercam essas substâncias químicas utilizadas na agricultura. No contexto do agronegócio e das ciências biológicas, os agrotóxicos podem ser agrupados de acordo com seu modo de ação no cultivo das plantas, trazendo à existência algumas denominações mais perceptíveis na agricultura produtivista, como herbicidas, fungicidas, inseticidas e acaricidas, respectivamente, relativos ao controle de ervas daninha, fungos, insetos e ácaros. No entanto, os produtores de soja, ao se referir, de modo genérico, aos agrotóxicos, habitualmente, usam o termo "defensivos agrícolas", inferindo uma ideia de proteção aos alimentos durante o cultivo ou na pós-colheita, por atribuírem a esses compostos a proteção contra pragas e doenças, consideradas causadoras de transtornos da agricultura empresarial, já que podem resultar em prejuízos econômicos.

Por outro lado, alguns termos usados como sinônimo de agrotóxicos podem representar atividade tóxica no organismo, como o caso do "biocida", que traz em si o significado de "matar a vida", e quando usado visa se referir à substância com atividade tóxica sobre organismos que são alvo ou não de sua ação, ${ }^{25}$

No capítulo V da Constituição brasileira de $1988,{ }^{26}$ que trata da comunicação social, há referência a restrições legais na propaganda comercial de produtos, práticas e serviços que possam ser nocivos à saúde e ao meio ambiente, estando os agrotóxicos, o tabaco e as bebidas alcoólicas sujeitos a essas restrições.

Embora "agrotóxico" seja uma palavra muito utilizada no cotidiano das pessoas, nos textos analisados a palavra "evento" é colocada como seu sinônimo, no entanto, entendemos que para o senso comum essa palavra se aproxima mais da ideia de ter um compromisso (festa, reunião, 
agendamento médico, entre outros). Mas ao analisarmos criticamente sobre a utilização deste termo nos trechos ${ }^{\mathrm{c}}$ a seguir, podemos apreender seu real sentido:

Agilizar a liberação de eventos de diferentes empresas é fundamental para vencer esse desafio;

(...) é a falta de conhecimento ou ideologia, a impedir a liberação de novos eventos...

Este é um daqueles casos em que o visível, o que é dado imediatamente, esconde o invisível que o determina. ${ }^{13}$ Dessa forma, entendemos que "evento" é o elemento revelado utilizado com a intenção de atenuar o significado que a palavra agrotóxico pode despertar no senso comum, o de ser danoso para o meio ambiente.

Segundo Bourdieu, ${ }^{14}$ "nomear é fazer ver, é criar, levar à existência”. Uma nova denominação para os agrotóxicos pode ser compreendida como uma estratégia simbólica de minimização de tensões e de reconstrução do que tem sido rejeitado socialmente, desta forma garantindo e protegendo os discursos e interesses sociais de grupos hegemônicos.

\section{Consideraçóes finais}

Os agentes sociais, ao apreender os objetos simbólicos através dos esquemas de percepção e de apreciação, por Bourdieu denominado habitus, conferem sentidos e significados distintos a eles em suas práticas. A articulação dos elementos simbólicos em um jogo de disputas por capital financeiro e cultural se faz presente nas relações sociais entre os agentes envolvidos nas práticas relacionadas ao uso ou não dos agrotóxicos na produção de alimentos. No cenário analisado, os agentes representantes do agronegócio assumem uma posição hegemônica no jogo simbólico, revelando um desequilíbrio de forças no contexto social da agricultura brasileira, influenciado pela detenção de um expressivo capital econômico.

O sistema produtivo agrícola orienta, nas relações de produção, a posição dos agentes e dos mecanismos que permitem o acesso às posições. Desse modo, as práticas culturais podem permitir o alcance da distinção no e para um grupo social, onde o poder e o privilégio estão relacionados aos capitais econômico, cultural e simbólico, bem como na articulação de sentidos que esses capitais podem assumir em cada configuração social e temporal do campo.

Ao se apropriarem do conceito de sustentabilidade, utiliza-o como um argumento de convencimento para valorizar uma prática produtivista de cultivo, em que o uso de agrotóxicos

c Esses trechos foram extraídos de um dos textos consultados, que enfatizava o desconhecimento a respeito do uso de insumos químicos nas práticas agrícolas como um limitante para o avanço tecnológico no campo e, consequentemente, o aumento da produtividade. 
se traduz em uma tecnologia moderna, capaz de maximizar o potencial produtivo, fomentando o fortalecimento de uma ideologia produtivista dominante que, no cotidiano, apresenta uma ideia de que o aumento da produção de alimentos é socialmente desejável.

No jogo simbólico presente no contexto do produtivismo agrícola há uma interface, que precisa ser considerada, entre a operacionalização tecnológica do cultivo e a necessidade de uma publicidade positiva para o uso de insumos químicos. Para tanto, os agentes que se aliam ao uso desses compostos utilizam como estratégia uma tentativa de ressignificar o nome "agrotóxico", que se apresenta desgastado socialmente, substituindo-o pelo termo "evento". Este é um artifício que se configura como um recurso de ocultação que pode determinar o que deve ser visto pelo sujeito receptor da mensagem.

Vale destacar que os agrotóxicos e sua relação com o ambiente podem ser pensados por todos os agentes das instituições governamentais, de modo coletivo, cujas competências legais sejam exercidas para uma avaliação da utilização responsável desses insumos, concentrando os esforços em uma conjunção de parâmetros políticos, morais, éticos e sociais. As práticas dos agentes sociais submissos às forças dominantes, representados por sujeitos aliados aos preceitos da agricultura de base agroecológica, no contexto desta pesquisa, podem ser conduzidas para construção de novos caminhos visando à saúde coletiva, com estratégias no jogo simbólico que levem mais à transformação do que à reprodução social, como dito por Bourdieu.

\section{Referências}

1. Centro de Estudos Avançados em Economia Aplicada. PIB Agronegócio-BR[Internet]. São Paulo: ESALQ/USP. [acesso em: 25 mar. 2014].Disponível em: http://cepea.esalq.usp.br/pib/

2. Medeiros LS. Luta por reforma agrária no Brasil contemporâneo: entre continuidades e novas questões. In: Grisa C, Schneider S,organizadores. Políticas públicas de desenvolvimento rural no Brasil. Porto Alegre: Editora da UFRGS; 2015. p.339-360.

3. Buttel FH.Transicionesagroecológicas em El siglo XX: análisis preliminar. Agricultura y Sociedad1995; 74:9-37.

4. Contreras J. A modernidade alimentar: entre a superabundância e a insegurança. História: Questões \& Debates 2011; 54:19-45.

5. 5.Fischler C. Gastro-nomie et gastro-anomie. Sagesseducorps et crise bioculturelle de l'alimentationmoderne. Communications 1979; 31(1):189-210.

6. Sambuichi RHR, Oliveira MAC, Silva APM, Luedemann G. A sustentabilidade ambiental da agropecuária brasileira: impactos, políticas públicas e desafios. Rio de Janeiro: IPEA; 2012. p.10-17. Texto para discussão no 1782. 
7. Sindiveg[Internet]. Dados estatísticos. Mensagem recebida por e-mail <veronicanaclara@gmail. com> em 20 mar. 2014.

8. Brasil. Agência Nacional de Vigilância Sanitária. Programa de Análisede Resíduos de Agrotóxicos em Alimentos (PARA). Relatório complementar relativoàsegunda etapa das análises de amostras coletadas em 2012. Brasília: ANVISA; 2014.

9. Brasil. Agência Nacional de Vigilância Sanitária. Programa de Análisede Resíduos de Agrotóxicos em Alimentos (PARA). Relatório de atividades de 2011 e 2012.Brasília: ANVISA; 2013.

10. 10.Brasil. Agência Nacional de Vigilância Sanitária. Programa de Análisede Resíduos de Agrotóxicos em Alimentos (PARA). Relatório de atividades. Resultados de 2009. Brasília: ANVISA; 2010.

11. Brasil. Agência Nacional de Vigilância Sanitária. Programa de Análisede Resíduos de Agrotóxicos em Alimentos (PARA). Relatório de Atividades de 2001-2007. Brasília: ANVISA; 2008.

12. Brasil. Decreto no 4.074, de 04 de janeiro de 2002 regulamenta a Lei no 7.802 de 11 de julho de 1989 que dispõe sobre a pesquisa, a experimentação, a produção, a embalagem e rotulagem, o transporte, 0 armazenamento, a comercialização, a propaganda comercial, a utilização, a importação, a exportação, o destino final dos resíduos e embalagens, o registro, a classificação, o controle, a inspeção e a fiscalização de agrotóxicos, seus componentes e afins, e dá outras providências. Diário Oficial da União 08 jan. 2002.

13. Bourdieu P. Coisas ditas. São Paulo: Brasiliense; 1990. 234 p.

14. Bourdieu P. Sobre a televisão seguido de a influência do jornalismo e os jogos olímpicos. Rio de Janeiro: Jorge Zahar; 1997. 144 p.

15. Bourdieu P.O poder simbólico. 16ª ed. Rio de Janeiro: Bertrand Brasil; 2012. 322 p.

16. Bourdieu P. A distinção: crítica social do julgamento. 2a ed. Porto Alegre: Zouk; 2013.

17. Jaspers K. Introdução ao pensamento filosófico. $4^{a}$ ed. São Paulo: Cultrix; 1965.

18. Aprosoja Brasil [Internet]. [acesso em: 02 out. 2012].Disponível em: http://aprosojabrasil.com.br/2014/

19. Agrodebate. Justiça nega pedido de suspensão para agrotóxicos com princípio 2,4-D [Internet]. 07 abr. 2014. [acesso em: 08 abr. 2014].Disponível em: http://g1.globo.com/mato-grosso/agrodebate/ noticia/2014/04/justica-nega-pedido-de-suspensao-para-agrotoxicos-com-principio-24-d.html

20. Brasil. Ministério do Meio Ambiente. Agenda 21 Global [Internet]. [acesso em: 03 jul. 2014].Disponível em: http://www.mma.gov.br/responsabilidade-socioambiental/agenda-21/agenda-21-global

21. Gadotti M. Educar para a sustentabilidade. Inclusão Social2008;3(1):75-78.

22. Atkinson G. La sostenibilidad como resilienciaen sistemas agroecológicos. In: Marín AC, editor. Agricultura y desarrollosostenible. Madrid: Ministerio de Agricultura, Pesca y Alimentación; 1995. p. 283-299.

23. Carvalho MCVS, Luz MT. Simbolismo sobre "natural" na alimentação. Ciênc Saúde Coletiva 2011;16(1):147-154. 
24. Furtado F. Ambientalismo de espetáculo: a economia verde e o mercado de carbono no Rio de Janeiro. Rio de Janeiro: Instituto Políticas Alternativas para o Cone Sul - PACS; 2012.

25. Moragas WM,Schneider MO. Biocidas: suas propriedades e seu histórico no Brasil. Caminhos de Geografia2003;4(10):26-40.

26. Brasil. Constituição (1988). Constituição da República Federativa do Brasil. Brasília, DF: Senado; 1988.

Recebido: 02/7/2016

Aceito: 31/8/2016 